\title{
Tuberculosis and One Health - What is in a Name?
}

\author{
Susanna Sternberg Lewerin * \\ Department of Biomedical Sciences and Veterinary Public Health, Swedish University of Agricultural Sciences (SLU), \\ Uppsala, Sweden
}

Keywords: zoonotic, tuberculosis, epidemiology, nomenclature, terminology

\section{INTRODUCTION}

Most control programs for bovine tuberculosis include reporting to both veterinary and public health authorities, and measures to prevent transmission from animals to humans. On the other hand, reporting of human cases to veterinary authorities is rare, unless an animal source is suspected. Exchange of data and strategic discussions between veterinary and public health authorities would strengthen tuberculosis surveillance in both animal and human populations.

A One Health approach is clearly warranted for tuberculosis. The disease has similarly serious consequences for humans and a broad range of animal species, and it has been strongly advocated as a One Health issue (1). Yet, tuberculosis cases in humans and animals are commonly treated as separate problems $(2,3)$.

Tuberculosis is caused by bacteria within the Mycobacterium tuberculosis complex (MTBC).

\section{OPEN ACCESS}

Edited by:

Guillermo Tellez,

University of Arkansas, USA

Reviewed by:

Kaori Sakamoto,

University of Georgia, USA

Sherry Layton,

Vetanco, Argentina

*Correspondence:

Susanna Sternberg Lewerin susanna.sternberg-lewerin@slu.se

Specialty section: This article was submitted to Veterinary Infectious Diseases, a section of the

journal Frontiers in Veterinary Science

Received: 21 August 2015 Accepted: 28 October 2015 Published: 11 November 2015

Citation:

Sternberg Lewerin S (2015) Tuberculosis and One Health -

What is in a Name?

Front. Vet. Sci. 2:54.

doi: 10.3389/fvets.2015.00054
"Bovine tuberculosis" usually means infection in cattle with Mycobacterium bovis $(3,4)$. However, this definition may be too restrictive, and the term bovine tuberculosis has been proposed to signify infection in cattle with any bacteria in the $\operatorname{MTBC}(5,6)$. Similarly, "human tuberculosis" usually refers to infection in humans with M. tuberculosis, while "zoonotic tuberculosis" refers to human infection with $M$. bovis (7). However, for control and monitoring purposes, as well as a One Health approach, it would be preferable to use the terms "human tuberculosis" and "bovine tuberculosis" for infection with all bacteria within the MTBC in humans and cattle, respectively. Consequently, infections in other host species could be named after the host species, complemented by specifying the infecting bacterial species. In the following, the term "tuberculosis" is used for infection with bacteria within the MTBC, regardless of host species.

\section{TUBERCULOSIS IN DIFFERENT HOST POPULATIONS}

Bacteria within the MTBC have a broad host range, although there are differences in host susceptibility as well as in the detailed pathophysiology of the infection $(4,8,9)$. Factors such as host species, individual immunity, route of infection, and infectious dose have a strong impact on the course of the disease, regardless of bacterial species $(8,10)$, and it may be difficult to discern the exact pathogenic peculiarities of each species.

Differences in the infectious dose for a certain host species via a certain route are reflected in the epidemiology of the disease in different populations $(8,10)$. In a high prevalence environment, the probability of exposure and infection is high for any susceptible host as seen in sporadic cases or outbreaks of tuberculosis in species, such as sheep, pigs, and horses.

Infection by $M$. bovis has been reported in a wide range of domesticated and wild animals. Although not as frequent a cause as M. tuberculosis, a substantial number of humans with tuberculosis are infected with $M$. bovis. The prevalence of $M$. bovis in human tuberculosis is generally higher 
in low-income regions with a high prevalence in cattle. However, it has been proposed that the global prevalence of $M$. bovis in humans is underestimated (11-15). In the absence of immunosuppression, human-to-human transmission of $M$. bovis is rare but has been observed $(15,16)$. Mycobacterium caprae, previously regarded as a caprine subtype of $M$. bovis, has also been identified as the causative agent of tuberculosis in domestic and wild animals, as well as humans.

Mycobacterium tuberculosis is most commonly isolated from people, but in regions with a high prevalence in the human population, the infection may spill over to animals. Most animal isolates of M. tuberculosis originate from cattle, pigs, dogs, and Indian elephants, but the infection has also been demonstrated in captive and free-living wildlife. Molecular epidemiology has demonstrated transmission between humans and animals, in both directions (17-20). Other MTBC species, such as Mycobacterium microti, Mycobacterium pinnipedii, and Mycobacterium africanum, have also been isolated from various host species. Genomic studies into bacterial evolution suggest that sea mammals, in addition to human dispersals, may have played a role in transmitting tuberculosis across the ocean in Pre-Columbian times, illustrating the complexity of the host-pathogen relationship (21).

\section{EPIDEMIOLOGY OF TUBERCULOSIS IN DIFFERENT POPULATIONS}

Infectious dose and route of infection are important factors for the pathogenesis of the disease in individual hosts. Consequently, population dynamics, spatial distribution, contact patterns, and population sizes influence disease epidemiology. Efforts to categorize host species as "maintenance hosts" and "spillover hosts" are sometimes contradictory $(8,10,22)$, probably due to the fact that the populations of these species differ between regions and ecological systems. The maintenance population may consist of one or several host species, depending on how the effective critical community size is achieved in different ecosystems (23).

Detailed data, sufficient to demonstrate the epidemiology of different MTBC species in different host populations, are difficult to obtain. The epidemiology of the infection differs regionally as well as within different populations in the same region $(8,12,24)$.

A crucial aspect of epidemiological data collection is case definition. A case of human tuberculosis may be a patient with a smear-positive sputum sample, a tuberculin reactor, a patient from whom $M$. tuberculosis has been isolated, or a patient with samples positive for any bacteria within the MTBC. Similarly, animal cases may be defined as tuberculin reactors, animals with visible lesions post mortem, animals with histological lesions indicative of tuberculosis, or individuals with samples yielding $M$. bovis (or MTBC) in culture. Furthermore, the tuberculin test in animals may be performed as a single or comparative test in the skin of the neck or in the caudal fold, and the interpretation may be different in different situations (e.g., regarding all inconclusive reactions as positive, if a higher test sensitivity is prioritized above specificity) (25). Different case definitions may be used for different purposes, and this must be taken into account when drawing conclusions from data.

\section{OTHER ASPECTS AFFECTING PREVALENCE FIGURES}

Isolation of bacteria from each case would enable species identification and molecular typing to support epidemiological investigations. This is, however, not always feasible, and zoonotic transmission (in either direction) of tuberculosis may be overlooked.

In most regions of the world where the prevalence of tuberculosis in animals and humans is high, lack of resources means that diagnostics are insufficient for bacterial identification to species level. Even in high-income countries, diagnostics may rely on microscopy of sputum smears, histological examination of formalin-fixed tissue, culture on media not suitable for all MTBC species, or the use of DNA probes unable to distinguish between MTBC species $(7,13,22)$. For example, the addition of glycerol in culture media will enhance growth of $M$. tuberculosis but inhibit growth of $M$. bovis, while culture media for M. bovis should preferably include pyruvate $(4,13,22)$. Most diagnostic methods require some presumption about expected findings, and this will affect disease monitoring across different populations and geographical regions.

In the absence of bacteriological results, the clinical presentation of tuberculosis cases is sometimes used as an indicator of the causative agent. The primary manifestation of $M$. bovis in humans is usually extrapulmonary, but the proportion of pulmonary cases appears to be increasing $(12,26)$. Occupational exposure among farmers and abattoir workers usually leads to aerosol infection, this type of exposure may be more frequent in low-income countries with a high prevalence of tuberculosis in animals but where detailed data are scarce $(8,10,16,22,26,27)$. Site of infection is, therefore, not a solid basis for conclusions about the causative agent.

\section{WHAT IS IN A NAME?}

Terminology affects risk perception and behavior (28), a fact that is well known in the commercial world but not as commonly discussed in the scientific arena (29). The use of terms like bovine and human tuberculosis would be better applied to mean infection with MTBC in the respective host species. While acknowledging the difference between the species within MTBC and the need to identify each one in each case, it is important not to let the definition of the disease lead to too narrow a perspective, with possible lapses in tracing and control of the infection. Despite public awareness campaigns to combat human tuberculosis, knowledge of the risk presented by infected animals and vice versa can be poor (30), perhaps reflecting a failure in communication and or/awareness among the medical and veterinary professions. The use of terms like "human tuberculosis" and "zoonotic tuberculosis" $(2,3,26)$ as contrasting events is not helping disease control, although it may be seen as formally correct. 


\section{PUBLIC HEALTH AND ANIMAL DISEASE CONTROL}

The primary reason for tuberculosis control in animals is to protect public health. As cattle infected with members of the MTBC can shed the bacteria in milk, unpasteurized dairy products represent a public health risk. In many parts of the world, milk is heat-treated, but other dairy products may be made with raw milk. While pasteurization of all dairy products is crucial, tuberculosis control in cattle and other animals remain important for human and animal health $(1,10,12,22,24)$. However, all stakeholders may not support disease control efforts, which are perceived as too costly and cumbersome, and therefore, not justifiable, when milk is pasteurized anyway (31). There may be a risk that the progress of tuberculosis control in animals, in combination with pasteurization of milk, has made professionals in human and veterinary medicine less aware, or even ignorant, of the fact that tuberculosis does not restrict itself to one host population. A stronger collaboration between veterinary and public health is often called for, and this call for collaboration must be repeated until taken for granted, and fully implemented in surveillance and control activities.

Many of the most heavily infected regions in the world lack the resources and infrastructure needed to control tuberculosis in animals and humans, while the epidemiology may be entirely different from what has been seen in countries where the disease

\section{REFERENCES}

1. Kaneene J, Miller RA, Kaplan B, Steele JH, Thoen CO. Preventing and controlling zoonotic tuberculosis: a one health approach. Vet Ital (2014) 50:7-22. doi:10.12834/VetIt.1302.08

2. OIE. Terrestrial Code. Chapter 11.5 Bovine Tuberculosis (2015). Available from: http://www.oie.int/index.php?id=169\&L=0\&htmfile=chapitre_bovine_ tuberculosis.htm [Accessed August, 2015]

3. WHO. Factsheet N 104 Reviewed March 2015: Tuberculosis (2015). Available from: http://www.who.int/mediacentre/factsheets/fs104/en/ [Accessed August, 2015]

4. Quinn PJ, Markey BK, Leonard FC, FitzPatrick ES, Fanning S, Hartigan PJ. Veterinary Microbiology and Microbial Disease. 2nd ed. Oxford: Blackwell Science Ltd (2011).

5. SANCO/7059/2013. European Commissison Health \& Consumers DirectorateGeneral, Unit G2. Working Document on Causal Agents of Bovine Tuberculosis. Available from: https://www.visavet.es/bovinetuberculosis/data/wd/ SANCO-7059-2013_M.tuberculosis_complex.pdf [Accessed August, 2015]

6. SANCO/10067/2013. European Commissison Health \& Consumers DirectorateGeneral, Unit G5. Working Document on Eradication of Bovine Tuberculosis in the EU. Available from: http://ec.europa.eu/food/animal/diseases/eradication/ tb_workingdoc2006_en.pdf [Accessed August, 2015]

7. Müller B, Dürr S, Alonso S, Hattendorf J, Laisse CJM, Parsons SDC, et al. Zoonotic Mycobacterium bovis-induced tuberculosis in humans. Emerg Infect Dis (2013) 19:899-908. doi:10.3201/eid1906.120543

8. Biet F, Boschiroli ML, Thorel MF, Guilloteau LA. Zoonotic aspects of Mycobacterium bovis and Mycobacterium intracellulare complex (MAC). Vet Res (2005) 36:411-36. doi:10.1051/vetres:2005001

9. García-Jiménez WL, Benítez-Medina JM, Fernández-Llario P, Abecia JA, García-Sánchez A, Martínez R, et al. Comparative pathology of the natural infections by Mycobacterium bovis and by Mycobacterium caprae in wild boar (Sus scrofa). Transbound Emerg Dis (2013) 60:102-9. doi:10.1111/j.1865-1682. 2012.01321.x

10. Michel AL, Müller B, van Helden PD. Mycobacterium bovis at the animalhuman interface: a problem or not? Vet Microbiol (2010) 140:371-81. doi:10. 1016/j.vetmic.2009.08.029 has been eradicated from the animal population $(10,12,24)$. This presents new challenges.

\section{CONCLUSION}

A systematic collaboration between different professions and control systems, and a common nomenclature clearly separating the name of the host species from the infecting bacterial species are the first steps toward effective tuberculosis surveillance and control.

We should learn from history and not repeat the mistake of those who, upon Koch's discovery of different MTBC species, first assumed that bovine tuberculosis did not affect humans, leading to the pasteurization of milk for calves long before it was applied to milk for human consumption. The more careful attitude of some early scientists, proposing to omit the host designation of the different bacterial species in order to anticipate assumptions that they are limited to the host whose name they bear (32), should be remembered as we make scientific progress. Understanding the complex ecosystem of the multihost pathogens within the MTBC is necessary for disease control. There is an urgent need for scientific advances in order to meet the need for global tuberculosis control in all host populations, but this will require a new thinking as regards the ecology of tuberculosis and a practical application of the One Health concept.

11. Ritacco V, de Kantor IN. Zoonotic tuberculosis in Latin America. J Clin Microbiol (1992) 30:3299-300.

12. Cosivi O, Grange JM, Daborn JC, Raviglione MC, Fujikura T, Cousins D, et al. Zoonotic tuberculosis due to Mycobacterium bovis in developing countries. Emerg Infect Dis (1998) 4:59-70. doi:10.3201/eid0401. 980108

13. Drobniewski F, Strutt M, Smith G, Magee J, Flanagan P. Audit of scope and culture techniques applied to samples supplied for the diagnosis of Mycobacterium bovis by hospital laboratories in England and Wales. Epidemiol Infect (2003) 130:235-7. doi:10.1017/S0950268802008105

14. Smith RMM, Drobniewski F, Gibson A, Montague JDE, Logan MN, Hunt D, et al. Mycobacterium bovis infection, United Kingdom. Emerg Infect Dis (2004) 10:539-41. doi:10.3201/eid1003.020819

15. Pérez-Lago L, Navarro Y, García-de-Viedma D. Current knowledge and pending challenges in zoonosis caused by Mycobacterium bovis: a review. Res Vet Sci (2014) 97:S94-100. doi:10.1016/j.rvsc.2013.11.008

16. Sunder S, Lanote P, Godreuil S, Martin C, Boschiroli ML, Besnier JM. Humanto-human transmission of tuberculosis caused by Mycobacterium bovis in immunocompetent patients. J Clin Microbiol (2009) 47:1249-51. doi:10.1128/ JCM.02042-08

17. Ocepek M, Pate M, Zolnir-Dovc M, Poljak M. Transmission of Mycobacterium tuberculosis from human to cattle. J Clin Microbiol (2005) 43:3555-7. doi:10. 1128/JCM.43.7.3555-3557.2005

18. Regassa A, Medhin G, Ameni G. Bovine tuberculosis in cattle owned by farmers with active tuberculosis in central Ethiopia. Vet J (2008) 178:119-25. doi:10. 1016/j.tvjl.2007.06.019

19. Chen Y, Chao Y, Deng Q, Liu T, Xiang J, Chen J, et al. Potential challenges to the stop TB plan for humans in China; cattle maintain M. bovis and M. tuberculosis. Tuberculosis (2009) 89:95-100. doi:10.1016/j.tube.2008.07.003

20. Mittal M, Chakravarti S, Sharma V, Sanjeeth BS, Churamani CP, Kanwar NS Evidence of presence of Mycobacterium tuberculosis in bovine tissue samples by multiplex PCR: possible relevance to reverse zoonosis. Transbound Emerg Dis (2014) 61:97-104. doi:10.1111/tbed.12203

21. Bos KI, Harkins KM, Herbig A, Coscolla M, Weber N, Comas I, et al. PreColumbian mycobacterial genomes reveal seals as a source of new world human tuberculosis. Nature (2014) 514:494-7. doi:10.1038/nature13591 
22. de la Rua-Domenech R. Human Mycobacterium bovis infection in the United Kingdom: incidence, risks, control measures and review of the zoonotic aspects of bovine tuberculosis. Tuberculosis (2006) 86:77-109. doi:10.1016/j.tube.2005. 05.002

23. Haydon DT, Cleaveland S, Taylor LH, Laurenson MK. Identifying reservoirs of infection: a conceptual and practical challenge. Emerg Infect Dis (2002) 8:1468-73. doi:10.3201/eid0812.010317

24. Miller M, Olea-Popelka F. One health in the shrinking world: experiences with tuberculosis at the human-livestock-wildlife interface. Comp Immunol Microbiol Infect Dis (2013) 36:263-8. doi:10.1016/j.cimid.2012.07.005

25. OIE. Terrestrial Manual. Bovine Tuberculosis (2009). Available from: http://www.oie.int/fileadmin/Home/eng/Health_standards/tahm/2.04.07_ BOVINE_TB.pdf [Accessed August, 2015]

26. Dürr S, Müller B, Alonso S, Hattendorf J, Laisse CJM, van Helden PD, et al. Differences in primary sites of infection between zoonotic and human tuberculosis: results from a worldwide systematic review. PLoS Negl Trop Dis (2013) 7:e2399. doi:10.1371/journal.pntd.0002399

27. Pal M, Zenebe N, Rahman MT. Growing significance of Mycobacterium bovis in human health. Microbes Health (2014) 3:29-34. doi:10.3329/mh.v3i1.19779

28. Buckton $\mathrm{CH}$, Lean MEJ, Comber E. 'Language is the source of misunderstandings'-impact of terminology on public perceptions of health promotion messages. BMC Public Health (2015) 15:579. doi:10.1186/s12889-015-1884- 1
29. Dohle S, Siegrist M. Fluency of pharmaceutical drug names predicts perceived hazardousness, assumed side effects and willingness to buy. J Health Psychol (2014) 19:1241-9. doi:10.1177/1359105313488974

30. Kidane AH, Sifer D, Aklilu M, Pal M. Knowledge, attitude and practice towards human and bovine tuberculosis among high school students in Addis Ababa Ethiopia. Int J Livest Res (2015) 5:1-11. doi:10.5455/ijlr.20150202104134

31. Torgerson P, Torgerson D. Benefits of stemming bovine TB need to be demonstrated. Nature (2009) 457:657. doi:10.1038/457657d

32. Smith T. A comparative study of bovine tubercle Bacilli in man in relation to cattle. J Exp Med (1898) 3:451-511. doi:10.1084/jem.3.4-5.451

Conflict of Interest Statement: The author declares that the research was conducted in the absence of any commercial or financial relationships that could be construed as a potential conflict of interest.

Copyright (C) 2015 Sternberg Lewerin. This is an open-access article distributed under the terms of the Creative Commons Attribution License (CC BY). The use, distribution or reproduction in other forums is permitted, provided the original author(s) or licensor are credited and that the original publication in this journal is cited, in accordance with accepted academic practice. No use, distribution or reproduction is permitted which does not comply with these terms. 